\title{
X-ray photoelectron spectroscopy: A powerful tool for a better characterization of thin film materials
}

\author{
A LEVASSEUR*, P VINATIER and D GONBEAU ${ }^{\dagger}$ \\ ICMCB-ENSCPB-BP108-33402 Talence cedex France \\ ${ }^{\dagger}$ L.P.C.M.-URA 5624-2 avenue du Président Angot-64000 PAU, France
}

\begin{abstract}
X-ray photoelectron spectroscopy (XPS) is one of the most powerful tools to characterize thin films materials. To illustrate the use of XPS, some examples will be given on materials used as positive electrode in microbatteries.

Further analyses of the film to understand the redox process are quite difficult with conventional methods due to the amorphous nature of the cathode. Here surface methods like XPS are very useful. Two main kinds of information can be obtained from XPS analysis: the oxidation states, and the determination of atomic environments.

Different kinds of positive electrode materials were studied, titanium and molybdenum oxysulfides $\left(\mathrm{MO}_{y} \mathrm{~S}_{2}\right.$, $\mathrm{M}=\mathrm{Ti}$, Mo) and lithium cobalt oxide $\left(\mathrm{Li}_{x} \mathrm{CoO}_{2+y}\right)$ and have been illustrated in the present work. In light of the binding energies obtained for the reference compounds, several types of environments and different formal oxidation states have been found for the transition elements.

XPS is also very useful for following the oxydo-reduction mechanisms occurring during the intercalation and the de-intercalation of lithium, corresponding respectively to the discharge and the charge of the battery. After strict identification of each species, the evolution of their binding energies could be followed very easily. The XPS analyses of oxysulfides thin films at different stages of their cycling process have shown apparently good efficiency of the oxygen-rich compositions.

During the redox process, the results obtained have clearly shown the important contribution of the sulfur atoms beside the transition metal atom.
\end{abstract}

Keywords. XPS; thin film; molybdenum oxysulfide; titanium oxysulfide; lithium cobalt oxide; microbattery.

\section{Introduction}

Deposition technologies can well be regarded as the major key in several domains: microelectronics; protection against physical or chemical damage; coating of large surface area for optical and electrical properties; materials conservation and economics or the engineering and design flexibility. Various thin film deposition technologies are now available, namely:

(i) evaporative methods (vacuum evaporation, molecular beam epitaxy (MBE) ...), (ii) glow-discharge processes (sputtering, plasma processes ...), (iii) gas-phase chemical processes (chemical vapour processes, deposition, thermal forming processes ...) and (iv) liquid phase chemical techniques (electro-processes, mechanical techniques ...).

Some of these methods result in the thin films having chemical composition and physical properties entirely different from those of the starting material. One of the most significant examples is that of sputtering.

The principle of this technology is simple. Two electrodes are installed in a vacuum chamber, one of these,

*Author for correspondence the so-called target, serves as the material source for the film to be produced and is at a high negative potential. A substrate holder is situated opposite to the target, which can be earthed or applied to a floating potential. Furthermore, the holder can be heated or cooled. The positive ions produced in the gas discharge are then accelerated to the negative target. Upon bombardment of the target, these result in ejection of mainly neutral particles by impulse transfer phenomena. The ejected particles wander through the working gas and condense on the substrate. The energy range of the ions is usually between 10 and $5000 \mathrm{eV}$. The process of material erosion in the sputtering process is definitely determined by momentum transfer of the impinging ions on the atoms of the upper layers of the solid material of the target and has a faint resemblance to the behaviour of billiard balls (Pulker et al 1984; Schnegraf 1988).

Many parameters can influence the composition and the nature of the thin film, for example: (i) the power used for the deposition; (ii) the pressure in the deposition chamber; (iii) the partial pressure of reactive gas like $\mathrm{O}_{2}, \mathrm{~N}_{2}$ or $\mathrm{H}_{2} \mathrm{~S}$ which can be added to the discharge gas to induce a chemical reaction in the plasma and to change the chemical composition of the film (reactive 
sputtering); (iv) the distance between the target and the substrate; (v) the nature of the discharge gas; (vi) the temperature and the nature of the substrate.

Starting from a well-known material, used as the target, the resulting thin film can be completely different from the starting material and therefore must be characterized each time - one of the above listed parameters change-a so-called thin film is typically in the range of few micrometers in thickness. The characterization of the thin films is quite difficult because the material available to perform the analysis is generally only few milligrams.

For chemical composition, one of the most efficient techniques is the Rutherford backscattering spectrometry (RBS), but light elements (atomic number $<6$ ) cannot be analysed (thin films are deposited on pure carbon) by this technique. For these, proton-induced $\gamma$ emission (PIGE) can be used. X-ray diffraction (XRD) or transmission electron microscopy (TEM) are useful to determine the crystallization state of the material; the morphology being examined by scanning electron microscopy (SEM). Auger electron and secondary-ion mass spectroscopies (AES and SIMS) may be used to obtain composition depth profiles. X-ray photoelectron spectroscopy (called both as XPS or ESCA) is one of the most powerful tools to characterize thin film materials.

Two factors justify the research in the field of microbatteries: the mass production of industrial devices with their own power sources and their miniaturization. All the thin films which will be taken as example in this paper could be used as the positive electrode in microbatteries (a microbattery is designed and fabricated with the help of sputtering).

Some of us have obtained, starting from $\mathrm{TiS}_{2}$ and $\mathrm{MoS}_{2}$ target, respectively: titanium oxysulfides $\left(\mathrm{TiO}_{y} \mathrm{~S}_{z}\right.$ ) (Meunier et al 1989; Meunier et al 1991; Gonbeau et al $1991)$ and molybdenum oxysulfides $\left(\mathrm{MoO}_{y} \mathrm{~S}_{z}\right.$ ) (Gonbeau et al 1991; Meunier et al 1991; Schmidt et al 1994; Benoist et al 1994; Levasseur et al 1995). More recently lithium cobalt oxide was obtained, starting from $\mathrm{LiCoO}_{2}$ (Benquilou-Moudden et al 1998).

\section{X-ray photoelectron spectroscopy}

XPS is a well established surface analysis $(\sim 50 \AA)$ : it is one of the most straightforward, nondestructive investigation modes of the chemical and electronic structure of materials. XPS can also provide specific structural information which is particularly useful in the case of amorphous systems. An important advantage of XPS is its ability to characterize on chemical environments from the variations in binding energies of core levels or chemical shifts. These chemical shifts can be correlated with their atomic charges; generally as the positive character of an atom increases so does its core binding energies. Thus the accurate determination of core level energies provide information on local chemical environments of atoms, electronic transfers, formal oxidation states.

There are two secondary, but important, probes: (i) the satellite peaks, and (ii) the valence band spectra. While the former provides additional fingerprinting of the chemical environment, the latter provides the valence band spectra related closely to the occupied density of states structure.

The XPS data are analysed by using peak synthesis programme on the basis of different factors deduced from study of the reference compounds.

\section{Experimental}

For the XPS analysis, surface science instruments spectrometer (model 301) was used, by focusing (the diameter of the irradiated area was $300 \mu \mathrm{m}$ ) monochromatized $\mathrm{A} 1 / \mathrm{K} \alpha$ radiation $(1486.6 \mathrm{eV})$. The residual pressure inside the analysis chamber was of the order of $3.75 \times 10^{-10}$ Torr.

The spectrometer was calibrated using the photoemission lines of gold (Au4f $f^{7 / 2}, 83.9 \mathrm{eV}$, with reference to the Fermi level) and copper $\left(\mathrm{Cu} 2 p^{3 / 2}, 932.5 \mathrm{eV}\right)$; for the $\mathrm{Au} 4 f^{7 / 2}$ line, the full width at half-maximum (FWHM) was $0.86 \mathrm{eV}$ under the recording conditions. The peaks were recorded with a constant pass energy of $50 \mathrm{eV}$.

The molybdenum and titanium oxysulfide thin films were prepared at room temperature by r.f. magnetron sputtering. To avoid water contamination on both targets and thin films, the system was set up in a dry argon glove-box. The targets $(50 \mathrm{~mm}$ in diameter) were prepared from commercial powder $\mathrm{MoS}_{2}$ and $\mathrm{TiS}_{2}$, respectively. The thin layers obtained by r.f. sputtering, using these targets, were deposited on stainless steel substrates $(12 \mathrm{~mm}$ in diameter). To obtain high oxygen contents in thin films, pure oxygen was introduced into the chamber through a leak valve. To avoid any surface pollution each thin film was mechanically scraped in the XPS chamber.

The XPS signals were analysed using a peak synthesis programme in which a nonlinear background (Shirley 1972) is assumed and the fitting peaks of the experimental curve are defined, thanks to a combination of Gaussian $(80 \%)$ and Lorentzian $(20 \%)$ distributions. To clear up the discussion, the curve fits for the whole set of thin films have been obtained using fixed amplitude ratio, FWHM ratios and spin splits; the degrees of freedom have been limited for each doublet to chemical shift, amplitude and FWHM.

In order to allow the characterization by XPS, the intercalated and deintercalated species have been obtained using liquid electrolyte batteries. The electrochemical chain was $\mathrm{Li} / \mathrm{LiAsF}$-EC-PC-DME/intercalation material (EC, ethylene carbonate; PC, propylene carbonate; 
DME, dimethyl ethylene; proportions, $1: 1: 2$ ). Batteries were charged and discharged with $1 \mu \mathrm{Acm}^{-2}$ current density. The positive electrode was carefully washed with pure acetonitrile and dried. For easier presentation, our discussion deals with formal oxidation numbers associated with entire charges although many gradations can exist in reality.

\section{Molybdenum oxysulfide thin films}

\subsection{Thin films before intercalation}

A preliminary step before the analysis of the XPS spectra was the characterization of reference molybdenum oxides and sulfides: $\mathrm{MoO}_{2}, \mathrm{MoO}_{3}, \mathrm{MoS}_{2}$ and $\mathrm{MoS}_{3}$. These are associated with the following formal oxidation state $(+4)$ for $\mathrm{MoO}_{2}$ and $\mathrm{MoS}_{2},(+5)$ for $\mathrm{MoS}_{3}$ and (+6) for $\mathrm{MoO}_{3}$. The results obtained for the Mo $3 d$ and $\mathrm{S} 2 p$ peaks are listed in table 1 (Benoist et al 1995).

Different $\mathrm{MoO}_{y} \mathrm{~S}_{z}$ thin films corresponding to variable oxygen partial pressures in the input gas to the plasma have been analysed. The XPS spectra of the Mo $3 d$ and

\section{Mo(3d) peak}

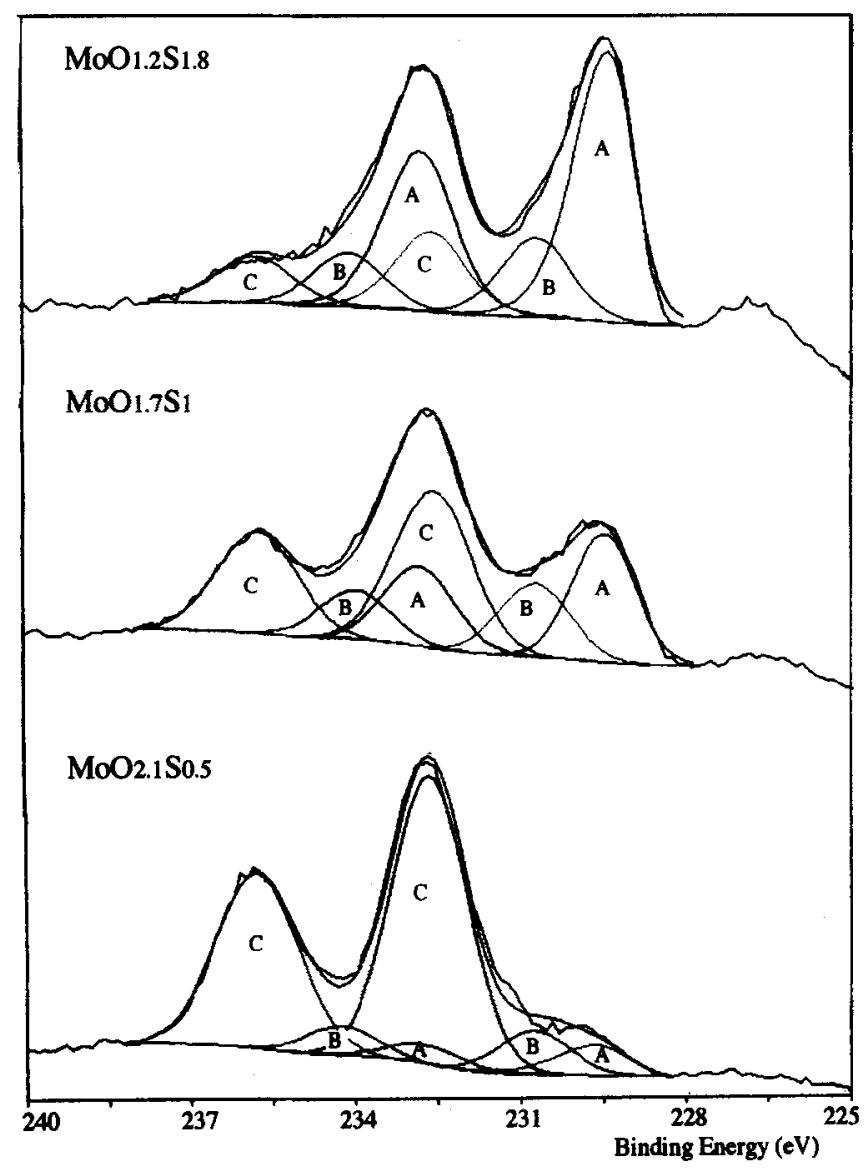

Figure 1. X-ray photoelectron spectra of the Mo $3 d$ in the $\mathrm{MoO}_{y} \mathrm{~S}_{z}$ thin films.
S $2 p$ levels are shown in figures 1 and 2 . The main results are summarized in table 2 .

The A doublet Mo $3 d$ is assigned to molybdenum atoms with a sulfur environment, as in $\mathrm{MoS}_{2}$. The $\mathrm{C}$ doublet undoubtedly results from molybdenum with oxygen, such as that in $\mathrm{MoO}_{3}$. The $\mathrm{B}$ doublet reveals a new molybdenum environment, because of its binding energy being different from all the references values (figure 1). In light of the evolution observed with the thin film compositions, the $S 2 p$ peak was broken down into three components (D, E and F) (figure 2). The $\mathrm{E}$ doublet corresponds to the same sulfur environment, $\mathrm{S}^{2-}$, which is present in $\mathrm{MoS}_{2}$, the $\mathrm{F}$ doublet is characteristic of disulfides $\mathrm{S}_{2}^{2-}$, however, no sulfur like that corresponding to the $\mathrm{D}$ doublet has been observed in the reference compounds; this sulfur is obviously $\mathrm{S}^{2-}$, the real effective charge of which is more negative than the real charge of $\mathrm{S}^{2-}$ in $\mathrm{MoS}_{2}$.

Coming back to the $\mathrm{B}$ doublet Mo $3 d$ and considering its appearance at higher energies than in the sulfur compounds, this molybdenum obviously has oxygen in

\section{$S(2 p)$ peak}

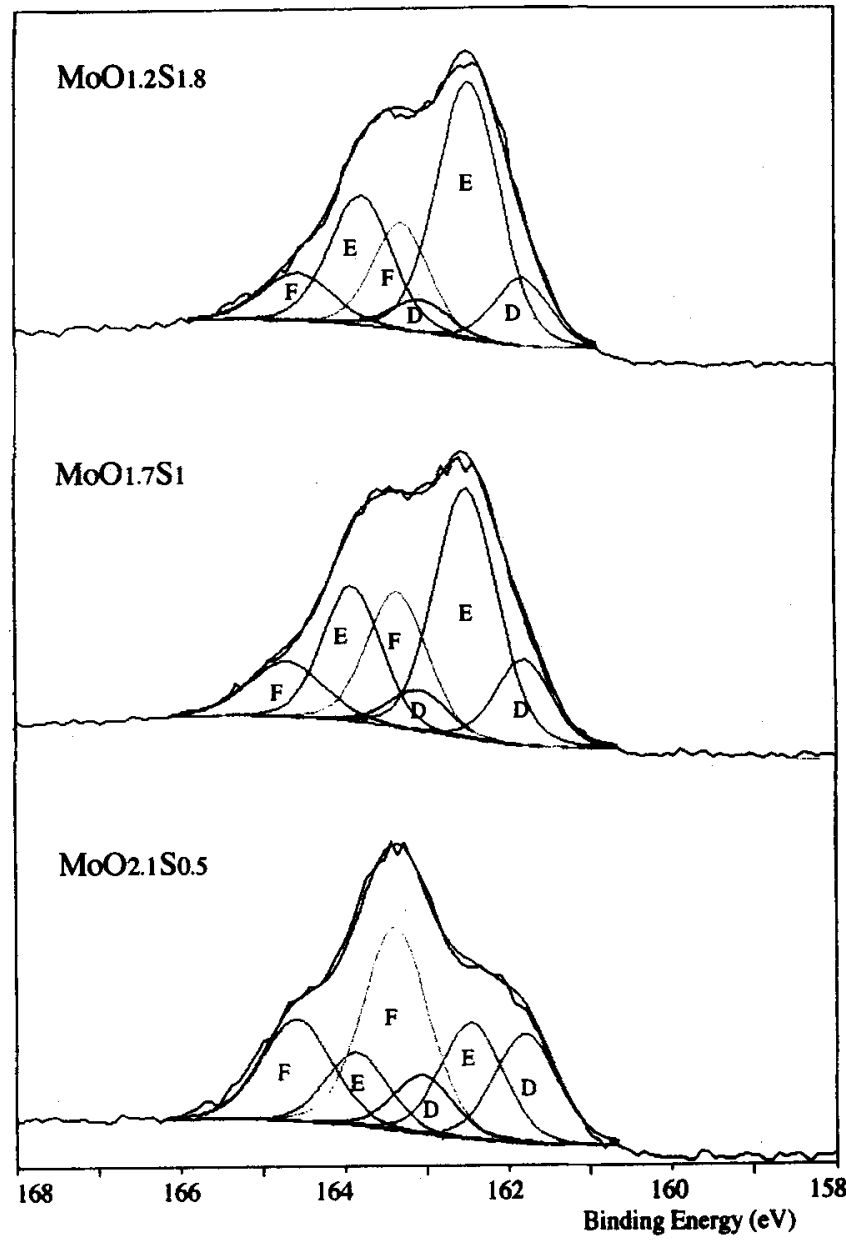

Figure 2. $\mathrm{X}$-ray photoelectron spectra of the $S 2 p$ level in the $\mathrm{MoO}_{y} \mathrm{~S}_{z}$ thin films. 
its environment. However, when the amount of oxygen rises, it should be noted that the $B$ doublet increases (in relation to the $\mathrm{A}$ doublet), as do both $\mathrm{D}$ and $\mathrm{F}$ doublets (in relation to $\mathrm{E}$ doublet) (see figures 1 and 2 , and table 2). Thus, sulfur ions also have to be considered as well as oxygen ions in the environment of this molybdenum; more precisely, disulfide ions $\mathrm{S}_{2}^{2-}$ (F doublet) and $\mathrm{S}^{2-}$ ions (D doublet), ions different from those present in $\mathrm{MoS}_{2}$ are very probably associated with the new species of molybdenum. This last $S^{2-}$ type sulfur ( $D$ doublet) being in a mixed environment, it will be indicated as ' $\mathrm{S}^{2-} \mathrm{ME}$ ' in the following sections.

Although XPS does not enable precise quantitative analysis, the study of the present data shows that this new « oxysulfide » molybdenum environment is composed of oxygen $\mathrm{O}^{2-}$ and sulfur $\left(\mathrm{S}_{2}^{2-}\right.$ and $\left.\mathrm{S}^{2-}\right)$ in equal proportions.

A comparison can be made between our work and an electron spin resonance (ESR) study. $\mathrm{MoO}_{y} \mathrm{~S}_{z}$ compounds were obtained after treatment at high temperature and under an oxygen pressure of bulky $\mathrm{MoS}_{2+x}$ compounds. The ESR spectra have shown a signal attributed to molybdenum atoms-an $\mathrm{Mo}^{5+}$ species-with oxygen and sulfur atoms as neighbours. In our analysis, similar environments have been chemically characterized by XPS in thin films of different $\mathrm{MoO}_{y} \mathrm{~S}_{z}$ compositions. It is also to be noted that the binding energies of $B$ doublet are close to values reported in the case of reduced unsupported Mo catalysts and assigned to $\mathrm{Mo}^{5+}$ species (Grünert et al 1991). Thus a (+5) formal oxidation state has been proposed for the «oxysulfide» molybdenum (B doublet).

\subsection{Thin film after intercalation}

To illustrate the behaviour of a thin film during intercalation and de-intercalation of the lithium, and to show the great contribution of XPS in the knowledge of the

Table 1. Mo $3 d$ and $S 2 p$ binding energies (electronvolts) in the reference compounds examined, with FWHM values in parentheses.

\begin{tabular}{|c|c|c|}
\hline & Mo $3 d_{5 / 2-3 / 2}$ & S $2 p_{3 / 2-1 / 2}$ \\
\hline $\mathrm{MoS}_{2}$ & $\begin{array}{l}229 \cdot 5-232.6 \\
(0.8) \quad(1 \cdot 0)\end{array}$ & $\begin{array}{l}162.4-163.6 \\
(0.85) \quad(0.85)\end{array}$ \\
\hline $\mathrm{MoS}_{3}$ & $\begin{array}{l}229 \cdot 3-232 \cdot 6 \\
(1 \cdot 1) \quad(1 \cdot 3)\end{array}$ & $\begin{array}{l}162 \cdot 2-163 \cdot 5 \\
(1 \cdot 15) \quad(1 \cdot 15) \\
163 \cdot 3-164.6 \\
(1 \cdot 15) \quad(1 \cdot 15)\end{array}$ \\
\hline $\mathrm{MoO}_{3}$ & $\begin{array}{l}232 \cdot 7-235 \cdot 8 \\
(1 \cdot 2) \quad(1.2)\end{array}$ & \\
\hline $\mathrm{MoO}_{2}$ & $\begin{array}{l}229.6-232.6 \\
(0.95) \quad(1.0)\end{array}$ & \\
\hline
\end{tabular}

material, the $\mathrm{MoO}_{2.4} \mathrm{~S}_{0.7}$ thin film composition was chosen. The evolutions of the Mo $3 d$ and S $2 p$ peaks are shown in figures 3 and 4 .

4.2a After the first discharge (intercalation of lithium): Very significant changes of the Mo $3 d$ and S $2 p$ peaks are detected. A strong decrease of the $C$ doublet is observed, the ' $\mathrm{Mo}^{6+}$ ' appears to be reduced. Simultaneously a new component is clearly distinguished on the low-energy side ( $G$ peak) (figure 3 ), its binding energy $(228.2-231.6 \mathrm{eV})$ is close to the value of the $\mathrm{Mo}^{0}$ doublet (228.2-231.5 eV-Mo metal); a small increase of the two other components is also detected (A and B doublets assigned, respectively to ' $\mathrm{Mo}^{4+}$ ' and ' $\mathrm{Mo}^{5+}$ ). The above results show a reduction of ' $\mathrm{Mo}^{6+1}$ to ' $\mathrm{Mo}^{6}$ ', that involves probably in a first stage, ' $\mathrm{Mo}^{5+}$ ' and ' $\mathrm{Mo}^{4+}$ '.

Concerning the $S 2 p$ peak after intercalation (figure 4 ), a strong increase of the $D$ doublet (' $S^{2-}(\mathrm{ME})$ ') and decreases of the $F$ and $E$ components (respectively ' $\left(\mathrm{S}_{2}\right)^{2-}$, and ' $\mathrm{S}^{2-3}$ as in $\mathrm{MoS}_{2}$ ) are observed. In addition, a new component appears on the low energy side ( $\mathrm{H}$ doublet); its binding energy $(160.9-162.2 \mathrm{eV})$ indicates a more negative sulfur, its value is close to the one of the $S$ $2 p$ peaks of $\mathrm{Li}_{2} \mathrm{~S}(160 \cdot 7-161.9 \mathrm{eV})$.

These changes correspond to a reduction of the pairs ' $\left(\mathrm{S}_{2}\right)^{2-}$, and of the ' $\mathrm{S}^{2-}$ sulfurs (as in $\mathrm{MoS}_{2}$ ) in sulfurs

Table 2. Mo $3 d$ and S $2 p$ binding energies (electronvolts) in the $\mathrm{MoO}_{y} \mathrm{~S}_{z}$ thin films, with the FWHM values in parentheses, and relative percentages.

\begin{tabular}{|c|c|c|c|}
\hline & $\mathrm{MoO}_{1.2} \mathrm{~S}_{1.8}$ & $\mathrm{MoO}_{1.7} \mathrm{~S}_{1}$ & $\mathrm{MoO}_{2.1} \mathrm{~S}_{0.5}$ \\
\hline \multicolumn{4}{|c|}{ Mo $3 d_{5 / 2-3 / 2}$} \\
\hline Peak A & $\begin{array}{l}229.5-232.7 \\
(1.2) \quad(1.4) \\
55 \%\end{array}$ & $\begin{array}{l}229.5-232.7 \\
(1.2) \quad(1.4) \\
30 \%\end{array}$ & $\begin{array}{l}229.6-232.8 \\
(1.3) \quad(1.5) \\
7 \%\end{array}$ \\
\hline Peak B & $\begin{array}{l}230.6-233.9 \\
(1.4) \quad(1.5) \\
27 \%\end{array}$ & $\begin{array}{l}230.7-233.9 \\
(1.4) \quad(1.5) \\
25 \%\end{array}$ & $\begin{array}{l}230.8-234.1 \\
(1.5) \quad(1.6) \\
13 \%\end{array}$ \\
\hline Peak C & $\begin{array}{l}232.6-235.8 \\
(1.5) \quad(1.5) \\
18 \%\end{array}$ & $\begin{array}{l}232 \cdot 6-235 \cdot 8 \\
(1.5) \quad(1 \cdot 5) \\
45 \%\end{array}$ & $\begin{array}{l}232 \cdot 6-235.9 \\
(1 \cdot 6) \quad(1 \cdot 6) \\
80 \%\end{array}$ \\
\hline \multicolumn{4}{|l|}{ S $2 p_{3 / 2-1 / 2}$} \\
\hline Peak D & $\begin{array}{l}161.8-163 \\
(0.9) \quad(0.95) \\
17 \%\end{array}$ & $\begin{array}{l}161 \cdot 8-163 \\
(0 \cdot 9) \quad(0 \cdot 95) \\
21 \%\end{array}$ & $\begin{array}{l}161 \cdot 8-163 \\
(0 \cdot 9) \quad(0 \cdot 95) \\
23 \%\end{array}$ \\
\hline Peak E & $\begin{array}{l}162 \cdot 5-163 \cdot 8 \\
(0 \cdot 9) \quad(1) \\
57 \%\end{array}$ & $\begin{array}{l}162 \cdot 5-163 \cdot 8 \\
(0 \cdot 9)(1) \\
53 \%\end{array}$ & $\begin{array}{l}162 \cdot 5-163 \cdot 8 \\
(0 \cdot 9) \quad(1) \\
25 \%\end{array}$ \\
\hline Peak F & $\begin{array}{l}163 \cdot 4-164 \cdot 7 \\
(1)(1) \\
26 \%\end{array}$ & $\begin{array}{l}163 \cdot 3-164 \cdot 6 \\
(1)(1) \\
26 \%\end{array}$ & $\begin{array}{l}163 \cdot 3-164 \cdot 6 \\
(1)(1) \\
52 \%\end{array}$ \\
\hline
\end{tabular}


characterized by a more negative real charge ' $\mathrm{S}^{2-}(\mathrm{ME})$ ' and ' $\mathrm{S}^{2-}$ ' (as in $\mathrm{Li}_{2} \mathrm{~S}$ ).

4.2b After the first charge (de-intercalation of lithium): A disappearance of the " $\mathrm{Mo}^{\prime \prime}$ ' is observed ( $\mathrm{G}$ peak) (figure 3 ) and the A and B peaks simultaneously increase; only a very slight modification of the $\mathrm{C}$ peak is observed in comparison with the previous stage (intercalation). These results show an oxidation of ' $\mathrm{Mo}^{\mathrm{n}}$ ' to ' $\mathrm{Mo}^{4+}$ and ' $\mathrm{Mo}^{5+}$, , only a small amount of molybdenum is reoxidized to ' $\mathrm{Mo}^{6+}$ '.

In the case of the $\mathrm{S} 2 p$ peak, the $\mathrm{H}$ doublet disappears and the $\mathrm{D}$ doublet decreases; in parallel, a significant increase of the $E$ peak and a smaller one of the $F$ peak are observed (figure 4). These modifications correspond to the oxidation of the most negative sulfur atoms but the reoxydation in disulfide pairs ' $\mathrm{S}_{2}^{2-}$ ' is not complete.

\section{$\operatorname{Mo}(3 d)$ peak}

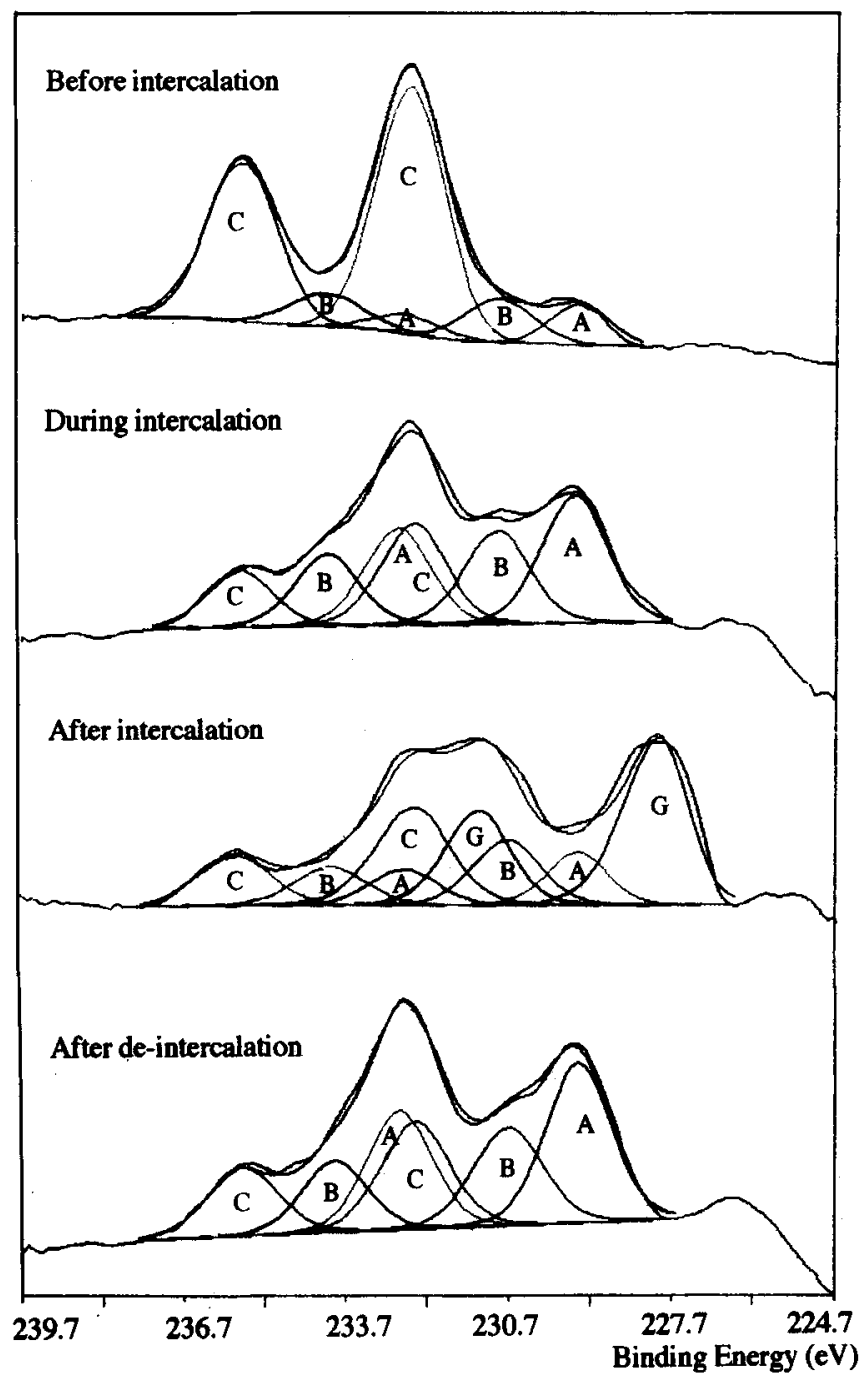

Figure 3. $\mathrm{MoO}_{2.4} \mathrm{~S}_{0.7}$ thin film: evolution of the Mo $3 d$ peak during lithium intercalation and de-intercalation.
In order to confirm this analysis, thin films of the same composition have been partially intercalated. Figures 3 and 4 show the Mo $3 d$ and S $2 p$ peaks after an interruption of the discharge, for $x=0.5$. It is to be noted that these spectra are very similar to the ones obtained after the charge. Furthermore, the ' $\mathrm{Mo}^{6+1}$ quantity (C doublet) does not change strongly between the partial intercalation and the end of the discharge, whereas a clear decrease of the ' $\mathrm{S}_{2}^{2-9}$ pairs ( $\mathrm{F}$ doublet) is observed between these two stages.

Thus, these results clearly indicate the important contribution of the sulfurs as well as of the transition metal during the redox processes.

Even though XPS does not enable a precise quantitative determination to be carried out, analysis of the results has shown that the ratio of $\mathrm{Li}$ to Mo atomic percentages is representative of the intercalation and de-intercalation

\section{$S(2 p)$ peak}

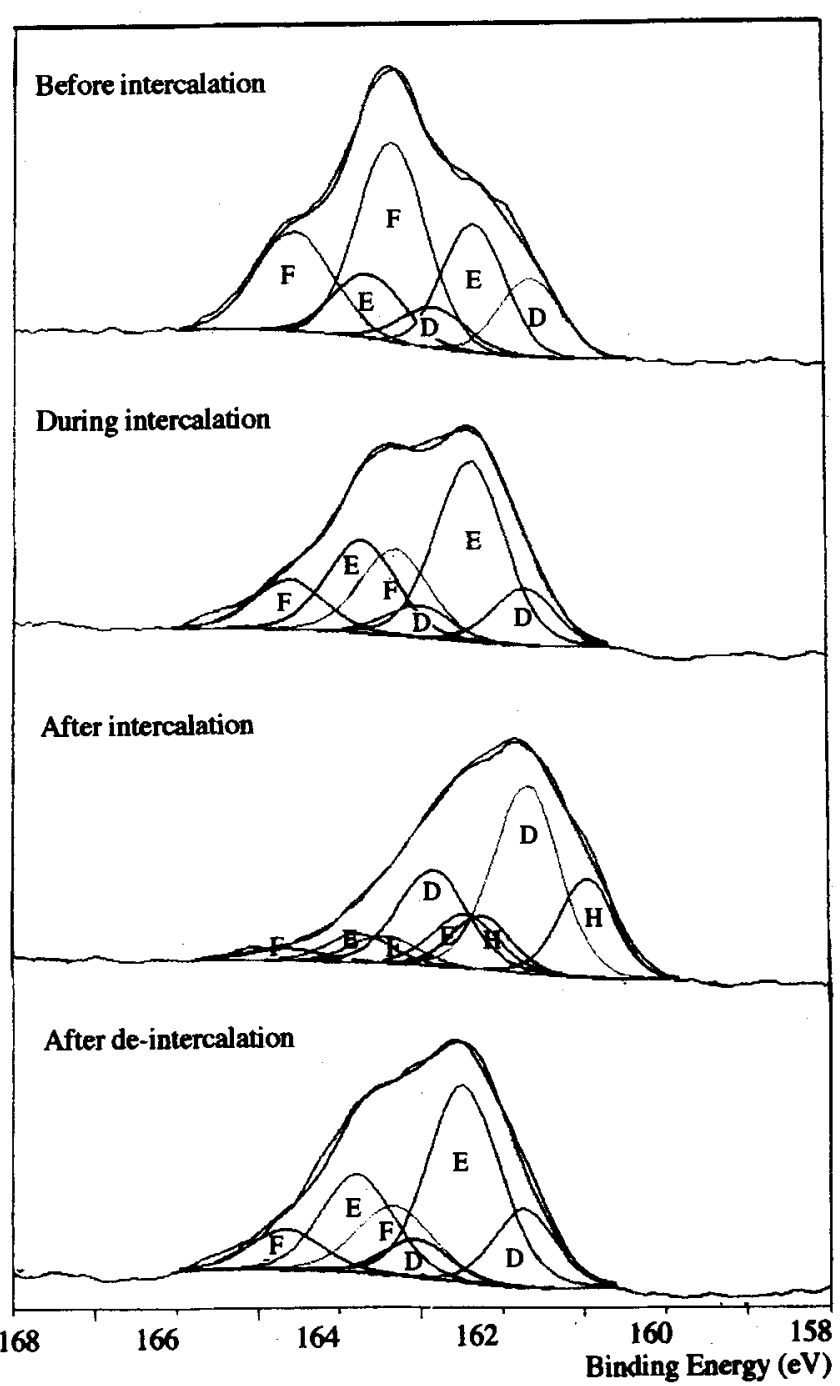

Figure 4. $\mathrm{MoO}_{2.4} \mathrm{~S}_{0.7}$ thin film: evolution of the $S 2 p$ peak during lithium intercalation and de-intercalation. 
processes. In relation with the gradations existing for the real charges associated with different oxidation numbers, it is difficult to correlate precisely the number of reduced atoms and the intercalation dose. However, on the basis of the atomic percentages for Mo $3 d$ and $\mathrm{S}$ $2 p$ components, the rough estimation of the electron count during the first discharge (about $3,3.2 e^{-}$) is in agreement with the intercalation of 2.9 lithium.

\section{Titanium oxysulfide thin films}

Different $\mathrm{TiO}_{y} \mathrm{~S}_{z}$ thin films corresponding to variable oxygen partial pressures in the input gas to the plasma have been also analysed. The XPS spectra of the Ti $2 p$ and $S 2 p$ levels are shown in figure 5 and the data reported in table 3 for one thin film $\mathrm{TiO}_{1.5} S_{1.7}$.

As for $\mathrm{MoO}_{y} \mathrm{~S}_{z}$ thin films, the results have shown the existence of three different environments for the metal atom, characterized by three doublets for Ti $2 p$ peak; corresponding to:

$$
\mathrm{TiO}_{1.5} \mathrm{~S}_{1.7}
$$

Ti(2p) peak
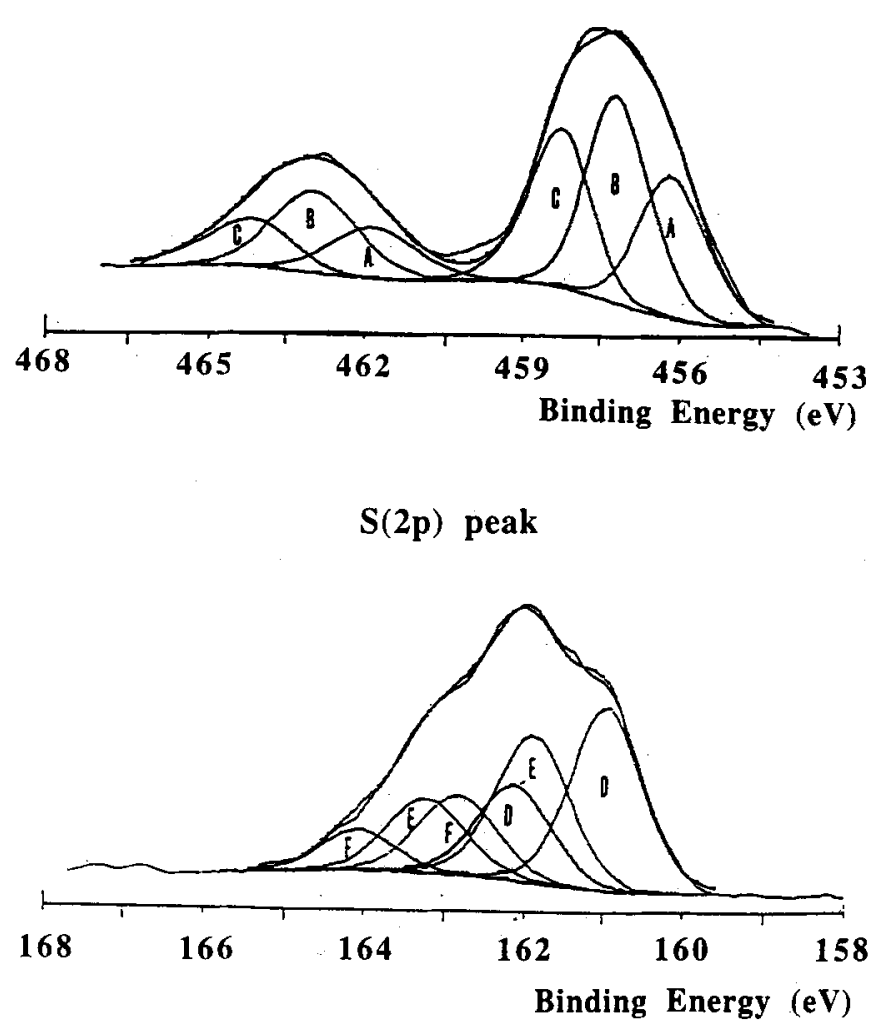

Figure 5. XPS spectra of the $\mathrm{Ti} 2 p$ and $\mathrm{S} 2 p$ levels in $\mathrm{TiO}_{1.5} \mathrm{~S}_{1.7}$ thin film.
- a sulfur environment as in $\mathrm{TiS}_{2}$ (A doublet)

- an oxygen environment as in $\mathrm{TiO}_{2}(\mathrm{C}$ doublet)

- an « oxysulfide» environment ( $\mathrm{B}$ doublet) composed of oxygen and sulfur ions in equal proportions.

This new type of environment appears in major proportion for some $\mathrm{TiO}_{y} \mathrm{~S}_{z}$ compositions contrary to $\mathrm{MoO}_{y} \mathrm{~S}_{z}$ thin films where it is always in minor proportions. In addition some differences appear in the analysis of $S 2 p$ peaks. Three types of sulfur atoms have been evidenced: (I) $\mathrm{S}^{2-}$ sulfurs as in $\mathrm{TiS}_{2}$ (D doublet); (II) $\mathrm{S}_{2}^{2-}$ disulfide pairs as in $\mathrm{TiS}_{3}$ (E doublet); and (III) $\mathrm{S}_{n}^{2-}$ polysulfide pairs (F doublet).

These last species are important in view of an enhanced contribution of the anions beside the transition metal atom in the redox processes.

\section{Lithium cobalt oxide thin films}

Following the same procedure as molybdenum and titanium oxysulfides, lithium cobalt oxide thin films were obtained (Benquilou-Moudden et al 1998). In this case also, XPS was very powerful to give better knowledge of these thin films.

Contrary to $\mathrm{MoO}_{y} \mathrm{~S}_{z}$, which are prepared without lithium (charged state), lithium cobalt oxide thin films are prepared in the discharged state.

After the characterization of some reference compounds like $\mathrm{CoO}, \mathrm{Co}_{3} \mathrm{O}_{4}, \mathrm{LiCoO}_{2}$ for $\mathrm{Co}^{2+}$ and $\mathrm{Co}^{3+}$ binding energies in these corresponding environment, $\mathrm{Ll}_{x} \mathrm{CoO}_{2}$ and $\mathrm{Na}_{4} \mathrm{CoO}_{4}$ for $\mathrm{Co}^{4+}$, a series of thin films were studied.

The evaluation of the $\mathrm{Co} / \mathrm{O}$ ratio has shown that all films studied are characterized by an excess of oxygen compared to crystalline $\mathrm{LiCoO}_{2}$.

The figures 6 and 7 show XPS spectra of one composition of lithium cobalt oxide for the Co $2 p$ and $\mathrm{O}$ $1 s$ levels and their evolution during the redox process. The starting material corresponds to $\mathrm{Li}_{1} \mathrm{CoO}_{2.5}$; after

Table 3. Ti $2 p$ and $\mathrm{S} 2 p$ binding energies (electronvolts) in the $\mathrm{TiO}_{1.5} \mathrm{~S}_{1.7}$ thin film, with the FWHM values in parentheses and relative percentages.

\begin{tabular}{|c|c|c|c|}
\hline & Ti $2 p_{3 / 2-1 / 2}$ & & S $2 p_{3 / 2-1 / 2}$ \\
\hline Peak A & $\begin{array}{l}456 \cdot 3-462 \\
(1.4) \quad(1.9) \\
28 \%\end{array}$ & Peak D & $\begin{array}{l}161 \cdot 1-162 \cdot 3 \\
(1 \cdot 1) \quad(1 \cdot 1) \\
45 \%\end{array}$ \\
\hline Peak B & $\begin{array}{l}457 \cdot 3-463 \cdot 1 \\
(1.4) \quad(1.9) \\
40 \%\end{array}$ & Peak E & $\begin{array}{l}162 \cdot 2-163 \cdot 4 \\
(1 \cdot 1) \quad(1 \cdot 1) \\
36 \%\end{array}$ \\
\hline Peak C & $\begin{array}{l}458.4-464.3 \\
(1.4) \quad(1.9) \\
32 \%\end{array}$ & Peak F & $\begin{array}{l}163 \cdot 1-164 \cdot 3 \\
(1 \cdot 1)(1 \cdot 1) \\
19 \%\end{array}$ \\
\hline
\end{tabular}




\section{$\operatorname{Co}(2 p)$ peak}

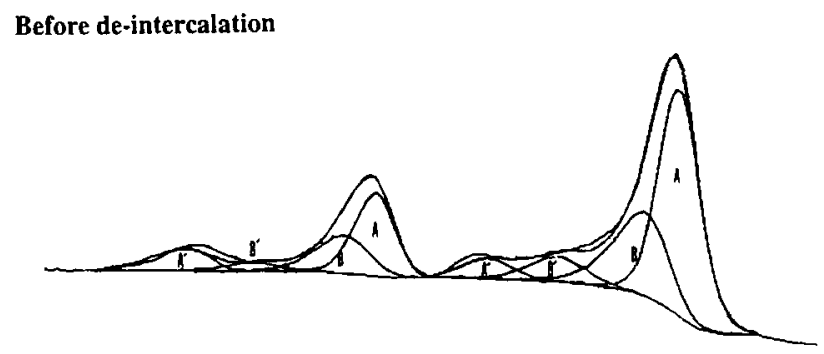

After de-intercalation

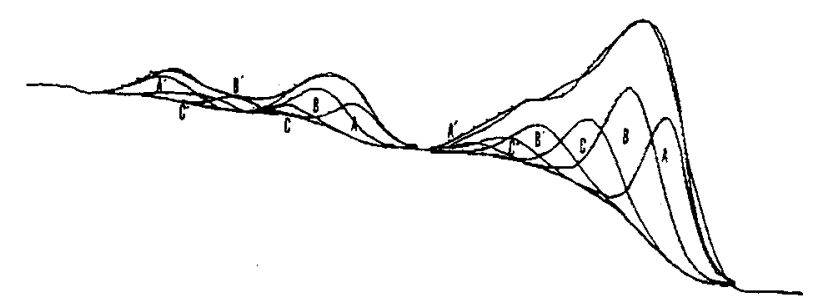

After re-intercalation

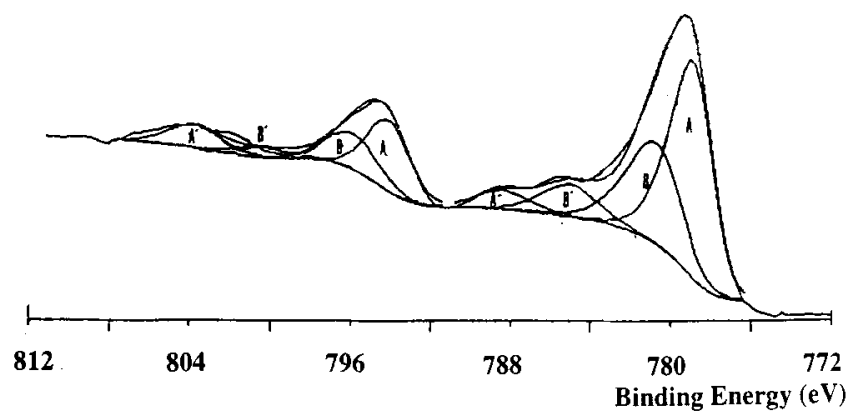

Figure 6. XPS spectrum for $\mathrm{Li}_{x} \mathrm{CoO}_{2.5}$ thin film for the $\mathrm{Co}$ $2 p$ level and its evolution during redox process $(x=1, x=0.25$ and $x=0.95$, respectively).

de-intercalation to $\mathrm{Li}_{0.25} \mathrm{CoO}_{2.5}$; and after re-intercalation to $\mathrm{Li}_{0.95} \mathrm{CoO}_{2 \cdot 5}$.

Before the de-intercalation of lithium, the A and B components of Co $2 p$ peak were assigned, respectively to $\mathrm{Co}^{3+}$ and $\mathrm{Co}^{4+}$ (cobalt atom) whatever the oxidation state is characterized by a main peak and a satellite at higher energy (around $9.5 \mathrm{eV}$.for $\mathrm{Co}^{3+}\left(\mathrm{A}^{\prime}\right)$ and $5 \mathrm{eV}$ for $\left.\mathrm{Co}^{4+}\left(\mathrm{B}^{\prime}\right)\right)$.

The $\mathrm{O} 1 s$ peak was broken down into two components $\mathrm{D}$ and $\mathrm{E}$, with the $\mathrm{D}$ one attributed to ' $\mathrm{O}^{2-}$ ' ions as in crystalline $\mathrm{LiCoO}_{2}$. In view of the analysis of different compositions $\mathrm{Li}_{x} \mathrm{CoO}_{2+y}$, the excess of oxygen was associated with the $\mathrm{E}$ component.

A similar peak (around $531 \mathrm{eV}$ ) was observed by several authors in studies of oxygen adsorption on nickel surfaces (Rajumon et al 1990; Rao et al 1990, 1995; Roberts 1994) or on polycristalline cobalt oxides (Chuang et al 1976; Jimenez et al 1995) but in the thin films the intensity is higher. The binding energy around $531 \mathrm{eV}$,

\section{O(1s) peak}

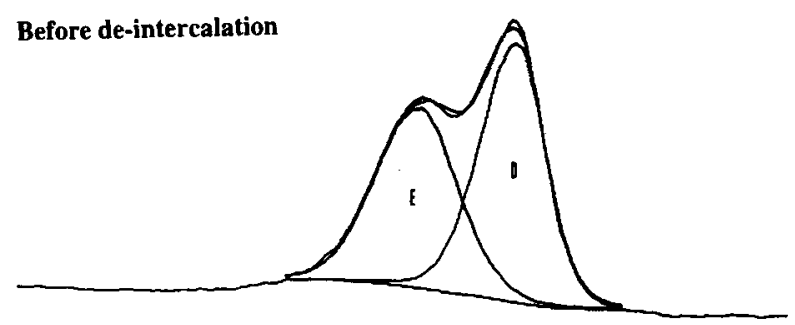

After de-intercalation
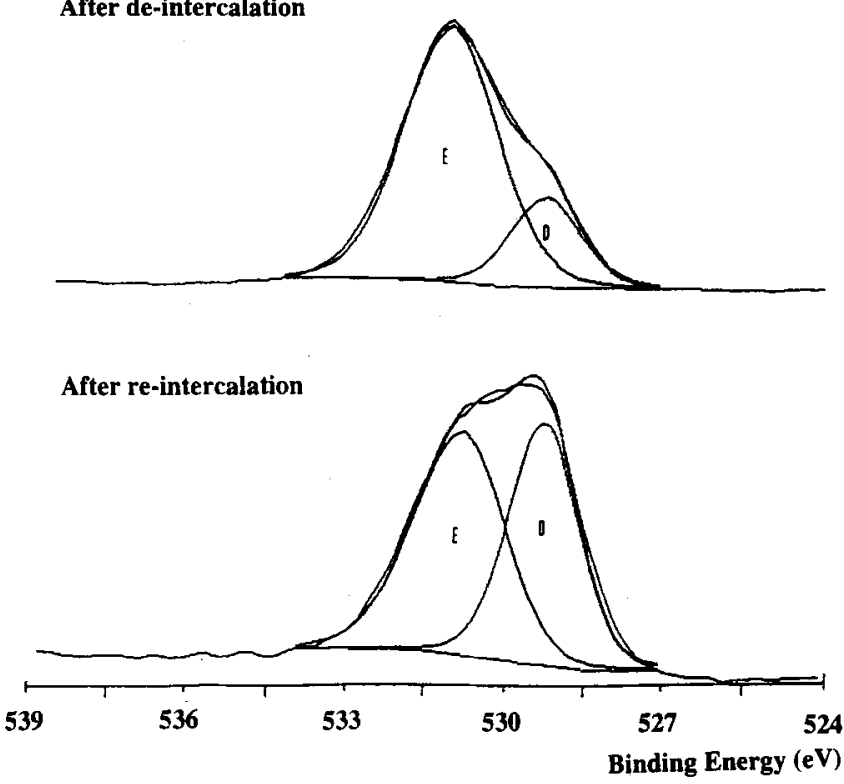

Figure 7. XPS spectrum for $\mathrm{Li}_{x} \mathrm{CoO}_{2.5}$ thin film for the $\mathrm{O} 1 s$ level and its evolution during redox process $(x=1, x=0.25$ and $x=0.95$, respectively).

corresponds to oxygen atoms that could be associated with particular coordinations in special sites or domains where the covalence of the $\mathrm{Co}-\mathrm{O}$ bond is higher.

After the de-intercalation of lithium (charged state) the B peak $\left(\mathrm{Co}^{4+}\right)$ increases and a third peak (C) appears which corresponds to cobalt slightly more oxidized than $4+$.

Concerning the $\mathrm{O} 1 \mathrm{~s}$ peak, an increase of the E peak and a decrease of the $D$ peak are observed. This corresponds to an oxidation of $\mathrm{O}^{2-}$ ions in $\mathrm{O}^{-}$ions similar to the peroxide ions characterized for $\mathrm{Na}_{2} \mathrm{O}_{2}$ and $\mathrm{SrO}_{2}$ $\left(\mathrm{Na}_{2} \mathrm{O}_{2}: \mathrm{E}_{\mathrm{b}}\left(\mathrm{O}_{2} 1 s\right)=530 \cdot 8 \mathrm{eV} ; \mathrm{SrO}_{2}: \mathrm{E}_{\mathrm{b}}(\mathrm{O} 1 s)=531 \mathrm{eV}\right)$.

After re-intercalation of lithium (2nd discharge) the $\mathrm{C}$ component of the $\mathrm{Co} 2 p$ peak disappears giving a spectrum very similar to the first one; the reversibility of the redox mechanism is complete.

The change of the $\mathrm{O} 1 \mathrm{~s}$ peak corresponds to a reduction process (a pollution due to the electrolyte, enhances the E component and does not allow to obtain the same spectrum as that of the first one). 


\section{Conclusion}

XPS is a very powerful tools for the characterization of thin film materials. After the study of chosen references, the different species found in the thin films could be identified and the evolution of each of them with the composition could be followed easily.

The examples selected, molybdenum and titanium oxysulfides and lithium cobalt oxide, have shown in oxysulfides several types of molybdenum or titanium environments and different sulfur ions; for lithium cobalt oxide two types of cobalt and two types of oxygen were evidenced.

The redox mechanisms could also be determined precisely following the evolution, the appearance, the disappearance of the peaks related to each kind of ion previously identified.

\section{References}

Benoist L, Gonbeau D, Pfister-Guillouzo G, Schmidt E, Meunier G and Levasseur A 1994 Surf. \& Interf. Anal. 22206

Benoist L, Gonbeau D, Pfister-Guillouzo G, Schmidt E, Meunier G and Levasseur A 1995 Thin Solid Films 258110

Benquilou-Moudden H, Blondiaux G, Vinatier P and Levasseur A 1998 Thin Solid Films 33316
Chuang T J, Brundle C R and Rice D W 1976 Surf. Sci. 59 413

Gonbeau D, Guimon C, Pfister-Guillouzo G, Levasseur A, Meunier G and Dormoy R 1991 Surf. Sci. 25481

Grünert W, Yu Stakhneev A, Feldhaus R, Anders K, Shpiro E S and Minachev K M 1991 J. Phys. Chem. 95 1323

Jimenez V M, Fernandez A, Espinos J P and Gonzalez-Elipe A R $1995 \mathrm{~J}$. Electron. Spectrosc. Relat. Phenom. 7161

Levasseur A, Schmidt E, Meunier G, Gonbeau D, Benoist L and Pfister-Guillouzo G $1995 \mathrm{~J}$. Power Sources 54352

Meunier G, Dormoy R and Levasseur A 1989 Mater. Sci. Eng. B3 19

Meunier G, Dormoy R and Levasseur A 1991 Thin Solid Films 20534,213

Pulker H 1984 Coating on glass (Amsterdam: Elsevier)

Rajumon M K, Prabhakaran K N and Rao C N R 1990 Surf. Sci. 233 L237

Rao C N R, Prabhakaran K N and Rajumon M K 1990 Surf. Solid State Science 4843

Rao C N R, Vijayaknishnan V, Kulkarni G U and Rajumon M K 1995 Appl. Surf. Sci. 84285

Roberts M W 1994 Surf. Sci. 299/300 769

Shirley D A 1972 Phys. Rev. B4 4709

Schmidt E, Weill F, Meunier G and Levasseur A 1994 Thin Solid Films 24534

Schnegraf K K 1988 Handbook of thin film deposition processes and techniques (London: Noyes Publications) 